\title{
DIFICULTAD, SOLIDARIDAD \\ Y REHABILITACIÓN: HACIA UNA MIRADA CRÍTICA DE LOS DISCURSOS SOBRE LA DISCAPACIDAD EN COLOMBIA ${ }^{1}$
}

\section{Difficulty, Solidarity and Rehabilitation: towards a Critical Look at the Discourse on Disability in Colombia}

John Jairo Uribe SARmiento

Universidad de Ibagué. Colombia

john.uribe@unibague.edu.co

Claudia Alejandra DuQue Romero

Universidad de Ibagué. Colombia

Leonor CÓRDOBA ANDRADE

Universidad del Tolima. Colombia

Recepción: 10 de febrero de 2016

Fecha de aceptación definitiva: 31 de mayo de 2016

Resumen: Durante los últimos años, se ha visto un creciente interés por indagar acerca de las narrativas que predisponen a las personas a establecer un determinado curso de acción hacia la población con discapacidad. El objetivo del estudio fue analizar los discursos dominantes sobre la discapacidad en Colombia, a través de la revisión de 42 videos de la Fundación Teletón, una institución que organiza un evento televisivo anual de 27 horas continuas, a través del cual se busca obtener recursos económicos para sostener centros de rehabilitación dedicados a brindar atención a población con discapacidad física. La ruta metodológica se trazó desde el análisis crítico del discurso de Van Dijk

1 Esta publicación es un producto del proyecto "Empoderamiento para el ejercicio pleno de sus derechos de niñas y mujeres con discapacidad, víctimas del conflicto armado colombiano", financiado por la Universidad de Ibagué, realizado entre los años 2013 y 2015. 
(1999). Los resultados dan cuenta de cuatro categorías a la luz de las cuales se agrupan los discursos: rehabilitación como panacea; discapacidad como algo difícil; solidaridad frente a la discapacidad como forma de persuasión de nosotros, frente a aquellos que requieren de nuestra ayuda; y la familia de personas con discapacidad como salvadora, se hace cargo de la discapacidad, como si fuera un problema individual. Se concluye que la estructura narrativa de los videos analizados converge en una representación de la discapacidad como algo triste, frustrante y limitante, que requiere de los héroes -la familia-y la solidaridad de una sociedad, que se mueve en la dualidad normalidad/anormalidad.

Palabras Clave: discapacidad; inclusión; discurso; representaciones sociales.

ABSTRACT: In recent years, it has seen a growing interest in inquiring about the narratives that predispose people to establish a course of action towards people with disabilities. The aim of this study was to analyze the dominants speech of disability in Colombia, trough the review of 42 videos of the Teletón Foundation, an institution that organizes an annual television event of 27 continuous hours, though which it seeks obtain financial resources to support rehabilitation centers dedicated to providing care to people with physical disabilities. The methodological path was drawn from the critical discourse analysis of Van Dijk (1999). The results shows four categories: rehabilitation as a panacea, disability as something difficult, solidarity towards disability as a persuasion from $u s$, against those who requires our help; and the people's family with disabilities, as a savior, who is in charge of disability, like the problem was personal. We conclude that the narrative structure of the videos analyzed converges on a representation of disability as something sad, frustrating and limiting that requires heroes -family-and solidarity from society that still moves prevalently in the duality normality/abnormality.

KEY WORDS: disability; inclusion; speech; social representations.

\section{Introducción}

$\mathrm{E}$ N ESTE ARTÍCULO SE ABORDA LA CUESTIÓN respecto a la efectividad del discurso social que se crea alrededor de las personas con discapacidad. Específicamente, se plantea una pregunta: ¿cuáles son los componentes centrales del discurso socialmente eficaz sobre la discapacidad? Para resolver esta inquietud, se parte de un supuesto: las narrativas son discursos eficaces en tanto generan efectos de verdad, al producir referentes capaces de ordenar la realidad socialmente construida.

La eficacia del discurso de la discapacidad ha sido abordada desde diferentes perspectivas. En un proceso de investigación sobre la inclusión educativa en Bogotá (Uribe, 2010), se desarrolló un ejercicio para identificar las actitudes y orientaciones cognitivas de 435 estudiantes de primaria sobre la discapacidad. Se les solicitó a los niños y niñas que escribieran el final de una historia que empezaba así: "Un día llega al salón una niña en silla de ruedas y la profesora la ubica junto a ti, entonces...”.

A partir de esa instrucción, los niños desarrollaban su propia narración. El análisis de estas historias evidenció la persistencia de una estructura narrativa: los niños preguntaban a la niña en silla de ruedas por el origen de su discapacidad, para luego

(C) Ediciones Universidad de Salamanca / CC BY-NC-ND

Siglo Cero, vol. 47 (2), n. ${ }^{\circ} 258,2016$, abril-junio, pp. 63-77 
mencionar algunas estrategias para ayudarla a recuperar la alegría. De esas historias, solo una no reproducía la misma estructura, pues allí la niña con discapacidad rechazaba la ayuda de sus compañeros para asumir una posición de liderazgo. Mientras en los demás relatos la niña se limitaba a responder las preguntas de los demás, en éste, ella hablaba con su propia voz ("no quiero que me miren con lástima”), preguntaba, criticaba y ordenaba (Uribe, 2010). Este tipo de actividades hipotéticas permiten identificar los referentes o coordenadas de sentido con los que los sujetos, en este caso los estudiantes de colegio, responderían a una situación similar.

Usualmente se considera que la eficacia social del discurso depende de su contenido de verdad. De modo que el discurso eficaz es aquel que se puede comprobar. Pero las cosas no son tan sencillas: la eficacia no depende del cumplimiento de ciertas "reglas” epistemológicas (aplicación de métodos de verificación), sino de toda una serie de condiciones: quién habla, en qué circunstancias y quién escucha (Foucault, 1992).

En este escenario es útil la noción de “categoría”, pues no sólo se trata de la estructura teórica que determina una visión del mundo, sino de las palabras que la constituyen. Las categorías utilizadas cotidianamente evidencian una concepción sobre la realidad, así como también un modo de verla (una perspectiva) y asumirla (una orientación ética y estética). Palabras como nación, pueblo, “discapacitado” son categorías a partir de las cuales se atribuye sentido al mundo.

Dicho esto, conviene señalar que a lo largo de la historia se ha definido la discapacidad a partir de la dualidad entre normalidad y anormalidad. Esta concepción dicotómica es evidente en los modelos discursivos predominantes en la comprensión de la discapacidad. Como lo señala Muñoz (2006), el fortalecimiento y legitimación del método anatomoclínico, vigente desde finales del siglo XVIII hasta inicios del XIX, refuerza enfáticamente esa perspectiva. La autora refiere el modo en que Foucault revisó las características de la mirada médica y cómo ésta determinó el lenguaje y el discurso sobre la discapacidad. A partir de ese enfoque médico, el "discapacitado" era considerado un sujeto improductivo debido a que no podía desempeñar ningún trabajo en las mismas condiciones de un cuerpo normalizado; por ello, automáticamente se convertía en "una carga pública” (Heller y Feher, 1995: 79; citados por Muñoz, 2006).

En contraposición, a principios del siglo XXI fue formulado el modelo social de la discapacidad con dos presupuestos fundamentales. El primero cuestiona los modelos que atribuían la discapacidad a creencias religiosas o planteamientos científicos, para adjudicarlo a condiciones sociales, de modo que la discapacidad empezó a ser concebida como un fenómeno social (Palacios, 2008). El segundo presupuesto establece "que lo que puedan aportar a la sociedad las personas con discapacidad se encuentra íntimamente relacionado con la inclusión y la aceptación de la diferencia” (Palacios, 2008: 104).

Hasta finales del siglo XX, la perspectiva médica planteaba que la discapacidad era un problema individual que debía ser “reparado” por medio de procesos médicos de rehabilitación. En contraposición, durante la última década del siglo XX ha cobrado fuerza el modelo biopsicosocial que reivindica la importancia de los factores biológicos, psicológicos, sociales y culturales. A partir de esta perspectiva, se evidencia el modo en que la sociedad y la infraestructura de los espacios cotidianos acentúan la

(C) Ediciones Universidad de Salamanca / CC BY-NC-ND

Siglo Cero, vol. 47 (2), n. ${ }^{\circ}$ 258, 2016, abril-junio, pp. 63-77 
condición diferencial de las personas con discapacidad, lo que agrega nuevos elementos al análisis (Stineman y Streim, 2010).

El abordaje de las narrativas sobre la discapacidad se refiere a la búsqueda de coordenadas de sentido institucionalizadas, repetidas, establecidas, que determinan su comprensión. Si la eficacia de los discursos es medida por su grado de determinación de la realidad, el presente análisis pretende identificar los discursos institucionalizados sobre la discapacidad con el objetivo de discutir sus efectos sociales, éticos y estéticos, en el espacio de la familia de las personas en esta condición.

La familia cumple un rol fundamental en la vida de las personas con discapacidad (Badia, 2005; Córdoba, Mora, Bedoya y Verdugo, 2007; Neeli y Dia, 2008; Peralta y Arellano, 2010), puesto que se constituye, en la mayoría de los casos, en el principal agente de inclusión social. No obstante, en esta perspectiva aún predomina una representación asistencialista, en la que impera la conmiseración y el deseo de "ayudar" a las personas con discapacidad; este discurso es propiciado, incluso, desde el propio microcontexto familiar, en el que se presenta a los demás integrantes de la familia como "salvadores del discapacitado", en contravía a los cambios globales y locales que se han experimentado en los últimos años en torno a los derechos de las personas con discapacidad (NU, 2006), que apuntan al fomento de su autodeterminación (Wehmeyer, 2006) y a su calidad de vida (Peralta y Arellano, 2010; Turnbull, Turnbull, Erwin, Soodaky y Shogren, 2011).

A partir de este marco de referencia, el objetivo del presente estudio fue analizar los discursos dominantes sobre la discapacidad en Colombia, desde la mirada crítica del discurso propuesta por Van Dijk (1999). Para ello, se escogió la producción audiovisual de la Fundación Teletón, dado que se constituye como un referente nacional para la atención a población con discapacidad, por lo que se infiere que su discurso contribuye a "instituir" lo que significa "la discapacidad". Teletón Colombia es, hoy en día, una fundación que trabaja con el propósito de contribuir a la rehabilitación de personas con discapacidad física y motora, y organiza anualmente un evento televisivo para recoger fondos para su funcionamiento ${ }^{2}$. Por esto, conviene subrayar que la discusión realizada a partir de estos resultados no se refiere al papel de la Fundación Teletón (si éste es o no positivo), tampoco pretende calificar la pertinencia o no del evento televisivo, sino que la intención de los autores es centrarse en el lugar de la discapacidad y cómo se la asocia culturalmente con la solidaridad.

\section{Metodología}

Con el fin de establecer las estructuras discursivas que determinan la discapacidad, se diseñaron matrices para analizar el material audiovisual seleccionado. Teniendo

2 El evento televisivo anual que organiza la Fundación Teletón de Colombia cuenta con la participación de figuras de la televisión, el espectáculo, medios de comunicación y autoridades en general, para recaudar fondos para el funcionamiento de los Centros de Rehabilitación con los que cuenta la fundación en diversas ciudades de Colombia. Adicionalmente, Teletón Colombia forma parte de ORITEL, la Organización Internacional de Teletones que tiene como objetivo apoyar a los países en cuanto a la organización y desarrollo de teletones e institutos de rehabilitación, y que busca, además, coordinar el intercambio de conocimientos y experiencias médicas en el campo de la rehabilitación, especialmente, en América Latina. 
en cuenta la propuesta metodológica de Van Dijk (1999), estas matrices fueron construidas a partir de dos preguntas: ¿cómo se representa la discapacidad en los videos analizados? y ¿qué tipo de efectos se espera producir en los espectadores?

Van Dijk plantea que el análisis crítico del discurso permite aproximarse a las ideologías sociales, aquellas constituidas por los procesos de cognición y la circulación del discurso: "Las ideologías son los sistemas básicos de la cognición social, conformados por representaciones mentales compartidas y específicas a un grupo, las cuales se inscriben dentro de las creencias generales (conocimiento, opiniones, valores, criterios de verdad, entre otros)" (Van Dijk, 1999: 1). De modo que para realizar un análisis, desde la perspectiva de este autor, es necesario tener en cuenta la interrelación entre los elementos que estructuran la cognición, la sociedad y el discurso.

Siguiendo a Van Dijk (1990), los discursos son unidades de lenguaje que cuentan con una dimensión textual y otra contextual. En la dimensión textual se manifiestan las representaciones cognitivas, es decir, las reglas internas del discurso o texto, mientras en la dimensión contextual están presentes las reglas de comprensión del uso social del discurso. De acuerdo con ello, se plantearon las preguntas básicas para analizar los videos. La primera indaga respecto a los significados atribuidos a la discapacidad: sus representaciones, características y valores. La segunda pretende establecer los efectos del discurso, ya que los videos interpelan a los espectadores, introduciéndolos en una red de significados y emociones que se traducen en una actitud frente a la discapacidad.

Desde este enfoque, la relación entre discurso y poder es fundamental para el análisis. El poder social es aquel control que se ejerce sobre otras personas por parte de grupos o instituciones (control desde el discurso), es decir, el control moral. Ahora bien, para avanzar en este análisis, de cada uno de los videos se seleccionó el conjunto de proposiciones que lo componían.

\section{Muestra}

Se revisaron 42 videos disponibles en la página web de la Fundación Teletón, todos publicados en Youtube. El único criterio de selección fue que se tratara de un video publicado por la Fundación Teletón Colombia, durante el periodo 2010-2013 (tiempo en el que se han llevado a cabo los eventos televisivos de esta institución en el contexto colombiano). La duración de este material era variable, entre 41" y 6'8" aproximadamente. En la Tabla 1, se observa la distribución por categoría de los videos analizados.

\begin{tabular}{|l|l|}
\hline \multicolumn{2}{|c|}{ Tabla 1. Distribución de los videos de acuerdo con las categorías } \\
previamente establecidas
\end{tabular}

(C) Ediciones Universidad de Salamanca / CC BY-NC-ND

Siglo Cero, vol. 47 (2), n. ${ }^{\circ} 258,2016$, abril-junio, pp. 63-77

$$
-67-
$$


DIFICULTAD, SOLIDARIDAD Y REHABILITACIÓN: HACIA UNA MIRADA CRÍTICA DE LOS DISCURSOS SOBRE LA DISCAPACIDAD EN COLOMBIA

J. J. URIBE SARMIENTO, C. A. DUQUE ROMERO Y L. CÓRDOBA ANDRADE

\begin{tabular}{|l|l|}
\hline \multicolumn{2}{|c|}{ TABLA 1. Distribución de los videos de acuerdo con las categorías } \\
previamente establecidas
\end{tabular}

Nota: *En este tipo de videos se solicita el apoyo de la sociedad.

* Denominados por la Fundación “Teletón en vivo”.

\section{Procedimiento}

En una primera fase del estudio, se llevó a cabo una búsqueda rigurosa, durante seis meses, de los videos de Teletón Colombia en el periodo de tiempo definido -2010-2013-, hasta agotar todo el material de este tipo existente en la Red. Simultáneamente, se construyó una matriz de análisis que fue probada con cinco videos. A partir de este estudio piloto, se realizaron los ajustes que permitieron configurar la estructura de la matriz de análisis definitiva como se observa en la Tabla 2.

\begin{tabular}{|l|}
\hline \multicolumn{1}{|c|}{ TABLA 2. Matriz para el análisis de cada uno de los videos } \\
\hline Criterios de análisis \\
\hline Fuente y fecha de publicación \\
\hline Categoría del video (estructura narrativa) \\
\hline Resumen del video \\
\hline ¿Cómo se define la discapacidad? \\
\hline ¿A quién se dirige la noticia, a quién habla, quién podría o debería escuchar? \\
\hline Elementos comunes encontrados en todos los videos \\
\hline ¿Quién habla? (personajes principales, personajes secundarios, personajes ambientales) \\
\hline Hipótesis de trabajo \\
\hline Representaciones sobre la discapacidad \\
\hline Elementos audiovisuales (entonación, uso de metáforas) \\
\hline Frases de interés \\
\hline Inferencias \\
\hline Evidencias (expresiones textuales obtenidas en las fuentes revisadas) \\
\hline
\end{tabular}

Durante la segunda fase, se ejecutó un proceso de caracterización de cada uno de los videos a través de la matriz de análisis particular (Tabla 1). Posteriormente, se construyó una matriz general que compilaba los resultados representativos de los análisis individuales. A partir de lo consignado en esta matriz general se evidenciaron unas categorías emergentes y, a la luz de éstas, se escribieron los resultados. 
DIFICULTAD, SOLIDARIDAD Y REHABILITACIÓN: HACIA UNA MIRADA CRÍTICA DE LOS DISCURSOS SOBRE LA DISCAPACIDAD EN COLOMBIA

\section{Análisis}

En función de la información obtenida de las matrices de análisis, se establecieron estructuras narrativas frecuentes en cada una de las categorías de los videos seleccionados (Tabla 3 ).

\begin{tabular}{|l|l|}
\hline \multicolumn{2}{|c|}{ TABLA 3. Estructuras $\begin{array}{l}\text { narrativas definidas en función de la categoría } \\
\text { de los videos analizados }\end{array}$} \\
\hline \multicolumn{1}{|c|}{ Tipo de video } & \multicolumn{1}{c|}{ Estructura narrativa } \\
\hline Videos institucionales & $\begin{array}{l}\text { 1. La Teletón devuelve la felicidad a las personas con discapa- } \\
\text { cidad gracias a la rehabilitación. } \\
\text { 2. La felicidad que la Teletón pueda devolver a las personas } \\
\text { con discapacidad depende de la solidaridad de los colom- } \\
\text { bianos. }\end{array}$ \\
\hline $\begin{array}{l}\text { Historias de vida de personas } \\
\text { con discapacidad }\end{array}$ & $\begin{array}{l}\text { 1. Inicio: discapacidad infeliz. } \\
\text { 2. Desarrollo: rehabilitación heroica. } \\
\text { 3. Final feliz: las personas con discapacidad vuelven a ser feli- } \\
\text { ces junto a sus familias gracias a la rehabilitación que favo- } \\
\text { reció la Teletón. }\end{array}$ \\
\hline $\begin{array}{l}\text { Videos promocionales del evento } \\
\text { central de Teletón }\end{array}$ & $\begin{array}{l}\text { Dada la variación de los videos, no se asume una estructura } \\
\text { narrativa, y sólo se retoman los datos arrojados en la matriz } \\
\text { individual. }\end{array}$ \\
\hline Teletón en vivo & $\begin{array}{l}\text { Igual procedimiento que en el caso de los videos promociona- } \\
\text { les, debido a la variación de los videos. }\end{array}$ \\
\hline
\end{tabular}

\section{Resultados y discusión}

La información obtenida en las 42 matrices individuales se organizó en una matriz general compuesta por las cuatro proposiciones que aparecían de forma recurrente en los videos analizados:

1. La rehabilitación que devuelve la felicidad.

2. La dificultad de la condición de discapacidad.

3. La exigencia de la solidaridad con las personas con discapacidad.

4. El carácter heroico de las familias de las personas con discapacidad.

\section{La rebabilitación: ¡Estás listo para empezar a ser feliz!}

Esta categoría está compuesta por los discursos que promueven la rehabilitación como la oportunidad para que las personas con discapacidad alcancen la felicidad. Por ejemplo, en uno de los videos, un beneficiado por Teletón afirma: "La rehabilitación: ¡yo me sentí feliz!” (Video, Historia de vida de Leydi Girón, 2011). La rehabilitación como el camino de realización para las personas con discapacidad física se constituye en una creencia socialmente compartida, al ser enunciada de ese modo por la mayoría 
de las personas que aparecen en los videos (beneficiarios, presentadores, funcionarios, actores, entre otros).

Siguiendo lo mencionado por Van Dijk (1999), el tono empleado por las personas al utilizar las palabras rebabilitación y felicidad indica una relación que corresponde a la estructura propia del discurso. Cuando los hablantes imprimen fuerza a la enunciación de estas palabras, se establece un discurso de "autorrepresentación positiva”, es decir, el beneficiario de la Teletón puede acceder a la rehabilitación, fuente de felicidad. Esta estructura influye en la formación de los modelos mentales y, por ende, en las ideologías: "Comprensión y persuasión del discurso" (Van Dijk, 1999: 10), tal como puede observarse en las siguientes expresiones: "Teletón me sirve mucho porque me ayuda a rehabilitarme"; "Si yo pudiera caminar, pudiera jugar futbol, pero no puedo. Toca hasta que me hagan la cirugía” (Video, Historia de Yesid Téllez, 2011).

La rehabilitación no sólo es presentada como un "deseo" de las personas con discapacidad, sino que también es expresada por los profesionales de la salud entrevistados: "La necesidad de rehabilitación es urgente, simplemente porque es un derecho que ellos tienen, a tener un rol dentro de su familia, dentro de su comunidad" (Video, Historia de Jesús Almeida, 2010).

De forma análoga, los familiares entienden que la rehabilitación se constituye en un proceso que "da sentido" a la discapacidad: "La vida de Laura ya cambió mucho porque ella ya mantiene muy contenta"; "Desde que Teletón ayudó a mi hija, y al verla feliz, también soy feliz ahora" (Video, Historia de vida de Laura Tatiana, 2013). Así que las personas con discapacidad encuentran en la rehabilitación una oportunidad de vida: "Cada vez que hablamos de mi niñez es un poco triste y doloroso, en ese entonces no quería vivir, si no hubiera sido por Teletón, quién sabe qué estaría haciendo ahorita" (Video, Historia de Everyn Quintero, 2011).

Esa asociación entre rehabilitación y felicidad se articula con la comprensión de la discapacidad como una situación difícil y triste. Según Van Dijk "la influencia ideológica depende no solo de las estructuras del discurso, sino también de otros elementos contextuales, como las representaciones mentales de los receptores, sus ideologías e intereses" (1999: 155).

\section{La discapacidad: ;Difícil, triste e impactante!, pero operable}

La discapacidad es representada como una situación compleja que determina la vida de las personas y sus familias. Al incluir la narración de las historias de vida de las personas con discapacidad se pretende conmover al televidente, al punto que el presentador del evento dice: "Esto es impactante” [...]; "¡Son historias muy duras, historias muy fuertes, historias que llegan al alma y al corazón de los televidentes!” (Video promocional Teletón Colombia, 2013). Estas afirmaciones son realizadas mientras el presentador sostiene un pañuelo en sus manos como signo de llanto. Ese carácter dramático es tan acentuado que en uno de los videos se relaciona la discapacidad con "todos" los problemas que existen en el país: "Todas las circunstancias graves, todos los problemas que tenemos en este país: pobreza, educación, desempleo, conflicto, 
están reflejados en una persona discapacitada" (Intervención de un funcionario) (Video institucional Teletón Colombia, 2011).

De acuerdo con lo mencionado en los videos, las limitaciones para realizar actividades y la dependencia de los demás procuran un sentimiento de tristeza en las personas con discapacidad: "Yo me sentía triste, lloraba porque no podía ver a mis amigos, tampoco la profesora, no podía estudiar”. A esta situación se suma la sensación de rechazo:

Me sentía muy mal, yo estaba muy triste porque ya no podía estar en carrera. Estuve mucho tiempo encerrado porque salía con bastones y toda la gente me veía raro. Mucha gente me molestaba “ay que pobre chino, así paticojo" que no podía volver a jugar, que no podía volver a saltar, que no podía volver a hacer casi nada, que así sin el pie no podía jugar fútbol (llorando), cosas que a mí me molestaban mucho. Me pegaba duro en el corazón el saber que no tenía un pie. Acá en la ciudad nadie es amigo, si uno tiene algo ahí sí es amigo de uno; uno no tiene nada y lo tiran (Hombre adulto con discapacidad).

En todos los videos se encuentran expresiones discursivas de tristeza, en las que a menudo se emplea la palabra impacto: "Me impactó mucho, porque al llegar una niña físicamente muy bonita, con un rostro muy angelical, estaba en una silla de ruedas" (profesional de la salud que atiende en la Fundación Teletón) (Vídeo, Historia de vida de Sofía Delgado, 2013).

Esa conmoción emocional es referida en los videos con la descripción de las dificultades a las que se enfrentan las personas con discapacidad: “A veces el ver a mi hija que no puede correr, no puede jugar, no puede montar bicicleta, yo digo: Mi hija más adelante: ¿qué va a ser de ella, cómo va a ir a la universidad, cómo va a ir al colegio?, y yo quiero que ella cuando vaya creciendo no vaya viendo dificultad" (madre de familia de una niña discapacitada). El énfasis y la reiteración de la dificultad de la condición de discapacidad es una manera de persuadir al televidente a que emprenda "acciones solidarias"

Por medio de esa estructura narrativa, en los videos se pretende afectar la emotividad de los receptores de estos discursos. De acuerdo con Mareño, la perspectiva emotiva está “compuesta por definiciones románticas de sentido común, basadas en la sensibilidad, en los sentimientos de compasión y lástima hacia aquellas personas que se supone padecen una desgracia biológica inherente” (2012: 139). La retórica de la discapacidad (Mareño, 2012) se crea a partir de la dualidad entre conmiseración y admiración. "De esta manera se adquiere la centralidad de ideología de la caridad; es decir, el conjunto de ideas y creencias que justifican a priori la necesaria prestación de auxilio y asistencia a esta población" (Mareño, 2012: 140). "Sin embargo todos sabemos (¿todos sabemos?) que la discapacidad no es una condición a curar, a completar o reparar: es una construcción relacional entre la sociedad y un sujeto (individual o colectivo). La discapacidad toma cuerpo en un espacio situacional, dinámico e interactivo entre alguien con cierta particularidad y la comunidad que lo rodea” (Brogna, 2006: 2).

3 Es necesario mencionar que el discurso sobre la solidaridad presente en los videos analizados ameritaría una revisión mucho más amplia que excede los límites e intereses de este artículo. 


\section{Solidaridad en un solo clic: donar dinero es hacer feliz a una persona con discapacidad}

Para analizar la noción solidaridad, se tuvo en cuenta el uso de los pronombres nosotros, ellos y tú. El "nosotros" corresponde al modo en que una serie de personas (actores, cantantes, presentadores) expresan y demuestran que son solidarios con las personas con discapacidad, lo que se configura en un paradigma de bondad para los televidentes: "En Colombia tenemos que entender que la discapacidad es un tema que nos afecta a todos como familia, como ciudadanos, como país. Nosotros como colombianos debemos seguir promoviendo lo más importante que es la solidaridad que existe entre nosotros" (Actor colombiano de televisión) (Video promocional Teletón Colombia, 2011). A partir de ese "nosotros" se invita a colaborar: “ ¡Es muy fácil participar!” (Presentadora de televisión) (Video, ¿Cómo sembrar un sueño por Teletón?, 2013); "Hay que juntar el corazón y el bolsillo para colaborar" (Presentador de televisión) (Video promocional Teletón Colombia 2013 por Jorge Alfredo Vargas, 2013).

Por otro lado, cuando se emplean los pronombres esos o ellos con los que se alude a las personas con discapacidad. En cuanto a la segunda persona en singular (tú), esta se utiliza para dirigirse a los televidentes, a quienes se les sugiere asumir una actitud solidaria hacia la población con discapacidad. Además de esto, se adjudican cualidades positivas a las personas con discapacidad con el objetivo de procurar solidaridad con esta población: "Esos niños son muy... divertidos. Si tú les das un chance, si les das una oportunidad" (Iván Lalinde, Presentador de televisión).

En concordancia con Van Dijk (2004), este procedimiento discursivo implica una estrategia de manipulación, en tanto que procura el desarrollo de representaciones sociales específicas. De un lado se encuentra la comunidad del nosotros que debe apoyarlos a ellos, las personas con discapacidad. Ese uso de los pronombres evidencia los mecanismos de eficacia del discurso: "La eficiencia de estos mecanismos reside precisamente en que los oyentes se formen automáticamente los modelos mentales preferidos por los hablantes en cada ocasión futura, sin que estos tengan que repetir los mismos discursos. $\mathrm{Si}$ los discursos logran esto es porque han construido representaciones sociales, es decir representaciones mentales socialmente compartidas" (Van Dijk, 2004: 5).

$\mathrm{Al}$ revisar los enunciados reiterados en los videos, se puede establecer una cadena de significados que constituyen una ideología: la discapacidad es una situación triste y frustrante para las personas en esta condición y sus familias; las personas con discapacidad pueden ser felices si acceden a procesos médicos de rehabilitación; quienes presentan una discapacidad son buenas personas y merecen la solidaridad de los televidentes: "Ser solidario es sencillo, con un solo clic" (eslogan de la campaña de Teletón para el año 2003).

Siguiendo a Van Dijk:

Ni las ideologías ni las representaciones se forman de un momento para otro. Necesitan de discursos variados y repetidos respecto a eventos varios y a partir de varias fuentes. Para inocular una ideología [...] las élites simbólicas necesitan involucrarse en una manipulación ideológica masiva, por ejemplo en discursos y campañas políticas repetidas, historias en los medios, lecciones en los libros de texto, etc. [...] Las ideologías fundamentales de nuestra sociedad están basadas en prácticas discursivas difundidas (2004: 8). 
Otro elemento que contribuye a la construcción de esa ideología son los escenarios donde se desarrollan las historias de vida de las personas con discapacidad. En los videos analizados, las familias aparecen en su entorno cotidiano, el cual usualmente evidencia un alto grado de pobreza. Esta información incrementa la comprensión de la discapacidad como una situación de completa dificultad, ante la cual se debe asumir una actitud solidaria.

Desde la perspectiva de la psicología cognitiva, Lozano, Peña y Abril (199), refiriéndose a las representaciones mentales del mundo, afirman: "El marco es una estructura abstracta de conocimiento convencional que alberga representaciones conceptuales del mundo a la manera de una memoria semántica y de un banco de información y conocimiento" (p. 47). Así, la presentación de los hogares donde habitan las personas con discapacidad y sus familias lleva al televidente a asociar la precariedad de las condiciones sociales de pobreza a la discapacidad, consolidando esquemas cognitivos.

En este sentido, Benveniste menciona que:

Desde la lingüística, hablando de la subjetividad en el lenguaje, considera a los indicadores de la deixis, demostrativos, adverbios, etc., como organizadores de las relaciones espaciales y temporales en torno al sujeto, añade: estos elementos tienen en común la propiedad sólo en relación a la situación del discurso donde son producidos [...] Establecen las referencias de persona, espacio y tiempo que ubica el texto en un contexto que a la vez construyen (Benveniste, 1966 citado por Lozano et al., 1999: 51).

Por su parte, Coseriu "considera a la situación, como la operación mediante la que los objetos denotados se sitúan, y se ordenan con respecto a las circunstancias espacio-temporales del discurso mismo. Se puede observar la tendencia hacia la creación del contexto por el texto" (Coseriu 1978 citado por Lozano et al., 1999: 309).

\section{En la familia, los béroes sí existen}

Dentro de este discurso, se extiende el cuadro de tragedia personal generado por la condición de discapacidad a la familia y, fácilmente, se pierde de vista la mirada de la familia como un sistema (Bronfenbrenner, 1979; Turnbull et al., 2011). Esta perspectiva da continuidad a la consideración de la familia en torno a la persona con discapacidad, lo que conlleva pensar y sentir que todos los integrantes de la familia tienen que enfrentarse a una serie de esfuerzos y sacrificios en función de la persona con discapacidad, aun en contra de las propias necesidades individuales de sus integrantes. De forma particular, esa narrativa de sacrificio recae sobre la figura materna, quien, en la mayoría de los casos, se ocupa predominantemente de la atención -la mal llamada cuidadora-de la persona con discapacidad. Circunstancia que la obliga a renunciar a sus espacios individuales, proyectos personales y bienestar, por cuanto debe cumplir con su doble o triple rol, de mujer trabajadora (en lo público), madre-esposa y cuidadora (en lo privado).

Este fenómeno se debe a la actitud de sumisión adoptada por las familias de las personas con discapacidad pues, de acuerdo con Brogna (2006), es como si estuvieran "entrenados en conformarse (sobre todo si la discapacidad es congénita o adquirida 
tempranamente)”, “asumen la discapacidad como algo 'que les tocó', se hacen cargo de un problema individual sin el menor asomo de rebeldía” (Brogna, 2006: 7), cuando en realidad se trata de un problema social.

Para Mareño (2012) esto es consecuencia de las representaciones sociales existentes sobre la discapacidad. Por ejemplo, la infantilización que les es atribuida en el hogar a las personas en esta condición se relaciona con diferentes variables: dependencia (necesidad de ayuda del otro), heteronomía (las personas con discapacidad no pueden tomar decisiones por sí solas, por lo que es responsabilidad de los otros), vulnerabilidad (las personas con discapacidad son vulnerables por su condición biológica), entre otras.

Esas variables sitúan a la persona con discapacidad en una posición de inferioridad, frente a la cual sus familiares asumen el papel de "salvadores" o "héroes": "La familia sale a la terapia, el padre sube a su hijo a sus hombros y dice: Dios y santísima virgen, nos toca cargarlo, pero hasta donde la vida nos tenga... lo cargaremos" (padre de niño con discapacidad) (Video, Historia de vida de Jesús Almeida, 2010). Adicionalmente, es importante mencionar que las familias a menudo expresan el deseo de que sus hijos sean vistos como "normales", lo que evidencia la dicotomía con la que se define la discapacidad, entrelazada entre la normalidad y anormalidad. Así, se configura la representación del paciente como una víctima que sólo puede ser redimida por la práctica médica. Al respecto, Mareño (2012) afirma que estos discursos sobre la discapacidad, además de ser naturalizados por la sociedad, son reproducidos por los medios de comunicación como realidades “evidentes e indiscutibles”.

\section{Conclusiones}

Los videos analizados cuentan con una estructura narrativa que puede resumirse en tres enunciados: la discapacidad es una situación que limita, frustra y entristece; las familias se esfuerzan ayudando a la persona con discapacidad a tener una buena calidad de vida; esta situación de lucha sólo puede solucionarse por medio de la rehabilitación médica. La superación de las limitaciones físicas implica la recuperación de la felicidad: niños y niñas vuelven a jugar y a conquistar las calles, mientras que los familiares encuentran un solaz para reconciliarse consigo mismos y con la vida. A partir de este discurso, se convoca a la solidaridad, a que los colombianos aporten "su granito de arena" y contribuyan a la solución de esta problemática.

Como se ha señalado, ese discurso es reproducido en otros contextos (Mareño, 2012; Uribe, 2010) en los que se restringe la escucha de la voz de las personas con discapacidad. Al igual que en las narraciones de los niños y las niñas de Bogotá (Uribe, 2010), las personas con discapacidad parecen no tener voz y las pocas veces que son escuchados reproducen la misma estructura narrativa respecto a su situación. Esa falta de discursividad propia les impide abogar por su derecho a la dignidad para no ser tratados con lástima, desconociéndose, por un lado, lo promulgado por la Convención de los Derechos de las Personas con Discapacidad (NU, 2006) y, por otro, la comprensión de la discapacidad como un fenómeno social, que implica a la propia 
persona en esta condición, a su familia, a la comunidad, a la sociedad y a la cultura en general, como se explicita en el modelo biopsicosocial.

No obstante, la reivindicación de estos derechos ha sido respaldada por diferentes investigaciones relacionadas con la construcción del cuerpo y la discapacidad (Kiten y Litschitz, 2009). En éstas se invita a las personas con discapacidad a cuestionar los discursos reiterativos sobre su condición, de manera que puedan redefinir la noción de "normalidad" desde su perspectiva.

Para lograr este diálogo, es necesario comprender que la "normalidad” (y su correlato, la normalización) hace parte de las lógicas del poder que apuntan a la estandarización biológica y subjetiva de los individuos, de modo que correspondan a las necesidades sociales de producción y consumo. A esta lógica del poder se la conoce como biopolítica, en tanto se constituye en un conjunto de técnicas orientadas a la producción y administración de la vida (Foucault, 1977; Esposito, 2006). De acuerdo con el discurso de los videos, la rehabilitación de las personas con discapacidad les permite acceder a la felicidad, en tanto puedan integrarse al sistema productivo normalizado; en otras palabras, la felicidad es sinónimo de productividad. Ahora bien, de acuerdo con Foucault (1977) la normalización es más poderosa, cuanto más invisibles son sus mecanismos. Por ello, la promoción casi cultual de la "normalidad" es uno de sus mecanismos más eficaces, puesto que se erige casi como la única condición posible para la felicidad.

Para terminar, queremos llamar la atención a todas las organizaciones e instituciones de atención a la discapacidad, y a la sociedad en general, para que se reconozca plenamente el papel central de la familia en la vida de las personas con discapacidad. Pero es necesario que ese reconocimiento se plantee a partir de la comprensión de la familia como un sistema, con unas características particulares de cohesión y adaptabilidad, en el que lo que le sucede a un miembro de la familia tiene implicaciones en la vida de los demás integrantes. Con este llamado pretendemos evidenciar la necesidad de promover una atención centrada en la familia. Por ello, es urgente que sus necesidades sean identificadas y expuestas, con sus propias voces, ya que no pueden ser resueltas sólo con "ayudas económicas" - desde una visión puramente asistencialista de "beneficencia”- cuando la pretensión debería ser de contribución a su bienestar.

En la misma dirección, se convoca a los profesionales que trabajan en y para la discapacidad a abandonar “el 'estatus todopoderoso' de la rehabilitación” (Brogna, 2006: 2), para asumir, desde una perspectiva biopsicosocial, un trabajo inter- o transdisciplinario, en el que se reconozca la discapacidad como una creación social, significada dentro de una situación relacional. La discapacidad es el espacio contingente y arbitrario que se le asigna al sujeto, por lo tanto, su situación de desventaja aumenta o disminuye de acuerdo a su contexto social y económico. Por ello, la discapacidad no es un problema que solo implica al sujeto que la padece y su familia, sino también a la sociedad en la que se encuentra. Para ello, es necesario promover un discurso que evidencie la responsabilidad colectiva respecto a lo que significa la condición de discapacidad, puesto que "la sociedad que aún no acepta la diferencia, excluye a ese otro -como a muchos otros- que discrimina, desvaloriza y segrega" (Brogna, 2006: 2).

(C) Ediciones Universidad de Salamanca / CC BY-NC-ND

Siglo Cero, vol. 47 (2), n. ${ }^{\circ}$ 258, 2016, abril-junio, pp. 63-77 
DIFICULTAD, SOLIDARIDAD Y REHABILITACIÓN: HACIA UNA MIRADA CRÍTICA DE LOS DISCURSOS SOBRE LA DISCAPACIDAD EN COLOMBIA

J. J. URIBE SARMIENTO, C. A. DUQUE ROMERO Y L. CÓRDOBA ANDRADE

\section{Referencias bibliográficas}

BADiA, M. (2005). Calidad de vida familiar: La familia como apoyo a la persona con parálisis cerebral. Psychosocial Intervention, 14 (3), 325-341. Recuperado de: goo.gl/G77GPn el 25 de febrero de 2014.

Brogna, P. (2006). El nuevo paradigma de la discapacidad y el rol de los profesionales de la rehabilitación. Cadernos ESP, Ceará, 2 (2), 7-12. Recuperado de: goo.gl/7GzF4d el 1 de abril de 2014.

Bronfenbrenner, U. (1979). The ecology of human development. Cambridge: Harvard University Press.

Córdoba, L., Mora, A., Bedoya, A. y Verdugo, M. Á. (2007). Familias de adultos con discapacidad intelectual en Cali, Colombia, desde el modelo de calidad de vida. Psykhe, 16 (2), 29-42.

Esposito, R. (2006). Bíos. Biopolítica y filosofía. Buenos Aires: Amorrortu.

Foucault, M. (1977). Historia de la Sexualidad. Vol. 1. La Voluntad de Saber. México: Siglo XXI.

Foucault, M. (1992). El orden del discurso. Traducción de Alberto González Troyano. Buenos Aires: Tusquets Editores.

Kiten, E. y Litschitz, A. (2009). Demasiado cuerpo. En A. Rosato y M. A. Angelino (Coords.), Discapacidad e ideología de la normalidad. Desnaturalizar el déficit (pp. 117132). Buenos Aires: Noveduc.

Lozano, J., Peña, C. y Abril, G. (1999). Análisis del discurso. Hacia una semiótica de la interacción textual. Madrid: Ediciones Cátedra.

Mareño, M. (2012). El saber convencional sobre la discapacidad y sus implicaciones en las prácticas. En M. A. Angelino y M. E. Almeida (Comps.), Debates y perspectivas en torno a la discapacidad en América Latina (pp. 133-145). Paraná: Universidad Nacional de Entre Ríos. UNER. Facultad de Trabajo Social. E-Book. Recuperado de: goo.gl/wWcsrq el 7 de marzo de 2014.

Muñoz, P. (2006). Construcción de sentidos del mundo de la discapacidad y la persona con discapacidad. Estudio de casos. Cali: Litocencoa. Universidad del Valle.

Naciones Unidas (2006). Convención Internacional sobre los Derechos de las Personas con Discapacidad y Protocolo Facultativo. Recuperado de: goo.gl/hJIcjj el 18 de abril de 2015.

NeELi, S. y Dia, D. (2008). Families of children with disabilities: a review of literature and recommendations for interventions. Journal of Early and Intensive Behavioral Intervention, 5 (3), 93-107.

Palacios, A. (2008). El modelo social de la discapacidad: orígenes, caracterización, plasmación en la Convención Internacional sobre los Derechos de las Personas con Discapacidad. Colección CERMI n. ${ }^{\circ}$ 36. Recuperado de: goo.gl/9DDZv1 el 26 de febrero de 2014.

Peralta, F. y Arellano, A. (2010). Familia y discapacidad. Una perspectiva teórico-aplicada del Enfoque Centrado en la Familia para promover la autodeterminación. Electronic Journal of Research in Educational Psychology, 8 (3), 1339-1362. Recuperado de: goo.gl/wWcsrq el 01 de abril de 2014.

Stineman, M. y Streim, J. (2010). The Biopsycho-ecological Paradigm: A Foundational Theory for Medicine. NIH Public Access, 2 (11), 1035-1045. Recuperado de: goo.gl/ZMj3Z6 el 2 de abril de 2014.

Teletón Colombia (2010-2013). Historias de vida. Recuperado de: goo.gl/deEUUV en octubre de 2013. 
DIFICULTAD, SOLIDARIDAD Y REHABILITACIÓN: HACIA UNA MIRADA CRÍTICA DE LOS DISCURSOS SOBRE LA DISCAPACIDAD EN COLOMBIA

J. J. URIBE SARMIENTO, C. A. DUQUE ROMERO Y L. CÓRDOBA ANDRADE

Teletón Colombia (2011). Video institucional Teletón Colombia 2011. Recuperado de: goo.gl/xrXll9 el 11 de noviembre de 2013.

Teletón Colombia (2013). ¿Cómo sembrar un sueño por Teletón? Recuperado de: goo.gl/ inXWqX el 11 de noviembre de 2013.

Teletón (2013). Video promocional Teletón Colombia 2013. Recuperado de: goo.gl/kwlRtJ el 20 de octubre de 2013.

Teletón Colombia (2013). Video promocional Teletón Colombia 2013 Jorge Alfredo Vargas. Recuperado de: goo.gl/WMvL81 el 23 de octubre de 2013.

Turnbull, A., Turnbull, R., Erwin, E., Soodak, L. y Shogren, K. (2011). Families, Professionals, and Exceptionality: Positive Outcomes Through Partnerships and Trust. New Jersey: Pearson.

URIBE, J. (2010). Informe de Investigación: Inclusión escolar en la Localidad de Tunjuelito. Documento de trabajo. Bogotá: Departamento de la Ocupación Humana. Facultad de Medicina. Universidad Nacional de Colombia.

VAN DijK, T. (1990). La noticia como discurso. Comprensión, estructura y producción de la información. Barcelona: Paidós.

VAN DijK, T. (1999). Ideología. Una aproximación multidisciplinaria. Barcelona: Gedisa.

VAN DijK, T. (2004). Discurso y dominación. 25 años de análisis crítico del discurso. En Grandes conferencias en la Facultad de Ciencias Humanas. Facultad de Ciencias Humanas. (Trad. J. Lopera y F. Guerra-Acero). Bogotá: Universidad Nacional de Colombia).

Wehmeyer, M. (2006). Autodeterminación y personas con discapacidad severa. Siglo Cero, 37 (4), 5-16. 